\title{
A description of the larval development of Megabalanus azoricus (Pilsbry, 1916) reared in the laboratory
}

\author{
Maria Dionísio • Armindo Rodrigues • \\ Ana Costa
}

Received: 3 December 2012/Revised: 20 September 2013/Accepted: 8 October 2013/Published online: 7 November 2013

(c) Springer-Verlag Berlin Heidelberg and AWI 2013

\begin{abstract}
This study provides the first description of the larval development of the commercially exploited barnacle Megabalanus azoricus. It describes the changes in larval size and shape as well as the general morphology and duration of each larval stage. Embryos were obtained from gravid specimens collected at São Miguel Island and reared through six naupliar stages to the cypris stage in laboratory conditions. The planktotrophic nauplii reached the cypris stage after 14 days of hatching in individual cultures at $20{ }^{\circ} \mathrm{C}$ under natural illumination and fed with phytoplankton (Chaetoceros gracilis, Isochrysis sp., and Tetraselmis sp.). The nauplius of $M$. azoricus has a normal size compared with nauplii of other congeneric species, ranging between the $261 \mu \mathrm{m}$ (nauplius I) and $912 \mu \mathrm{m}$ (nauplius VI). This work provides the first description of larvae of the genus Megabalanus for the Portuguese oceanic islands and provides comparisons with congeneric species in other parts of the world.
\end{abstract}

Communicated by H.-D. Franke.

M. Dionísio $(\bowtie) \cdot$ A. Costa

CIBIO, Pólo dos Azores - Departamento de Biologia,

Universidade dos Açores, Rua Mãe de Deus, 13ª

9500-801 Ponta Delgada, Portugal

e-mail: amdionisio@uac.pt

A. Costa

e-mail: accosta@uac.pt

A. Rodrigues

CIRN, Departamento de Biologia, Universidade dos Açores,

Apt 1422, 9501-855 Ponta Delgada, Portugal

e-mail: rodrigues@uac.pt
Keywords Intertidal barnacles - Cirripedia · Megabalanus azoricus · Larval development . Oceanic Island · Azores

\section{Introduction}

Megabalanus azoricus is an insular Atlantic species inhabiting shallow subtidal bedrock of St. Helena Island, Azores, Madeira, and Canaries Archipelagos (Wirtz et al. 2006). This species is the largest and the most common shallow-water barnacle of the Azores, where it is one of the most prized seafood, although a threatened species because of heavy and increasing exploitation (Dionísio et al. 2007). It is currently proposed that $M$. azoricus be nominated as a species which requires urgent attention under the Convention for the Protection of the Marine Environment of the North-East Atlantic (OSPAR 2011). The World Wide Fund for Nature also considers $M$. azoricus as an endangered species (WWF 2010).

Larval recruitment is one of the major determinants of population dynamics in barnacles (e.g., Crisp 1976). The identification of larval stages in the plankton is essential to understand adult population dynamics and its relation to a changing environment. However, the lack of descriptions of $M$. azoricus larvae prevents plankton-based assessments of the species' local reproductive and recruitment activity.

The life cycle of a barnacle includes four major life stages: eggs, six free-swimming and feeding naupliar stages (except the first one), a single pre-settlement cypris, and the sessile adult. Barnacle nauplii are distinguished from nauplii of other crustaceans by the possession of the distinctive fronto-lateral horns on the carapace (Foster 1967). The distinction between the successive nauplius stages is mainly based on the morphology of appendages, 
size and shape of carapace, and the abdominal process (Crisp 1976; Lang 1979). The larvae of the Balanomorpha have a trilobed labrum, a pair of spines on the posterior margin of the cephalic shield between the stages IV-VI, whereas hispid spines are absent (Anderson 1994; Lee and Shim 2000).

Megabalanus azoricus is the only species of the family Megabalanidae, which occurs on the NE Atlantic Portuguese oceanic islands. Its larval development has not been described before and can provide important information for taxonomic studies and phylogenetic hypotheses. The knowledge of the life history of M. azoricus is also fundamental for a sustainable management of the species. Furthermore, recent studies to establish a commercial aquaculture of this species (Pham et al. 2008; López et al. 2010) have also emphasized the need for a detailed analysis of the species' larval development.

This paper is the first description of larvae of the genus Megabalanus for the Portuguese oceanic islands (Azores), providing detailed information on the duration, segmentation, and setal types of all stages. The findings are compared with those reported on congeneric species in other parts of the world.

\section{Materials and methods}

Barnacles of M. azoricus were obtained from the sea by scuba diving in São Miguel Island (Azores) in July 2009. The shells were broken, and ovigerous lamellae containing embryos with a nauplius eye were transferred to a beaker filled with filtered, permanently aerated seawater. Antibiotics (streptomycin sulfate and penicillin) were added to prevent bacterial contamination (Anderson 1994). The water was changed daily. Temperature $\left(20^{\circ} \mathrm{C}\right)$ and salinity (35) were similar to the ambient conditions (e.g., Yan 2003), and a long-day photoperiod (LD 16:8) was provided (Chan 2003). The basic culture method was slightly modified from Brown and Roughgarden (1985).

When mature ovigerous lamellae were removed from adults and placed in fresh seawater, first-stage nauplii (nauplii I) readily hatched and became active. The pronounced positive phototaxis of barnacle nauplii aggregates the young larvae at sites of maximum light intensity. At these sites, samples could be taken easily, which were then transferred to further containers or preserved. The larvae were inspected at 3-h intervals in stages I-III and every $6 \mathrm{~h}$ in the other stages.

Given their rapid molting to stage II, some newly hatched larvae were preserved in $70 \%$ ethanol immediately after hatching. Preserved exuviae and larvae were dissected with fine tungsten needles in a mixture of glycerin and alcohol. Drawings were made under a light microscope with a camera lucida, and measurements were performed with an ocular micrometer. Twenty larvae per stage were preserved in $70 \%$ ethanol for later inspection and description (e.g., Yan 2003). After hatching, larvae were fed with phytoplankton (Chaetoceros gracilis, Isochrysis sp., and Tetraselmis sp.).

The following measurements were taken for 10 larvae per stage: total body length (TL), measured from the anterior margin of the shield to the tip of the dorsal thoracic spine; shield width (SW), i.e., the greatest width of the body behind the fronto-lateral horns; shield length (SL), measured from the anterior to the posterior margin of the shield, excluding the posterior shield spines in naupliar stages IV, V, and VI; and lengths of the fronto-lateral horns (FL) and the posterior shield spines (SP) in stages IV, V, and VI. Following measurements were taken for the cypris stage: total length (TL), measured from the anterior to the posterior margin of the carapace; and cypris depth (CD), i.e., the distance between the dorsal and the ventral margin of carapace at the deepest point. The morphology of antennules, antennae, and mandibles was described using the setation formulae of Newman (1965) and the setal terminology of Lang (1979) and Branscomb and Vedder (1982).

The results of development duration, size of the larvae, and setal formula were compared with another species of the subfamily Megabalaninae/Megabalanus californicus (Miller and Roughgarden 1994); Megabalanus coccopoma (Severino and Resgalla 2005); Megabalanus tintinnabulum (Thiyagarajan et al. 1997); Megabalanus rosa; and Megabalanus volcano (Kado and Hirano 1994).

\section{Results}

\section{Culture of larvae}

The larval development of M. azoricus includes six naupliar stages and one cypris stage. The development thought the naupliar stages to the cypris took $14 \pm 2$ days at $20^{\circ} \mathrm{C}$ (Table 1).

\section{Larval morphology}

The nauplii of $M$. azoricus have a broad pear-shaped cephalic shield (Fig. 1), typical of balanoid larvae, with a pair of fairly short spines, but without dorsal and marginal

Table 1 Time to the appearance of the different larval stages of $M$. azoricus

\begin{tabular}{llllllll}
\hline & $\begin{array}{l}\text { Larval stage } \\
\text { I }\end{array}$ & II & III & IV & V & VI & Cypris \\
\hline Day of appearance & 0.5 & 1 & 3 & 7 & 9 & 12 & 14 \\
\hline
\end{tabular}




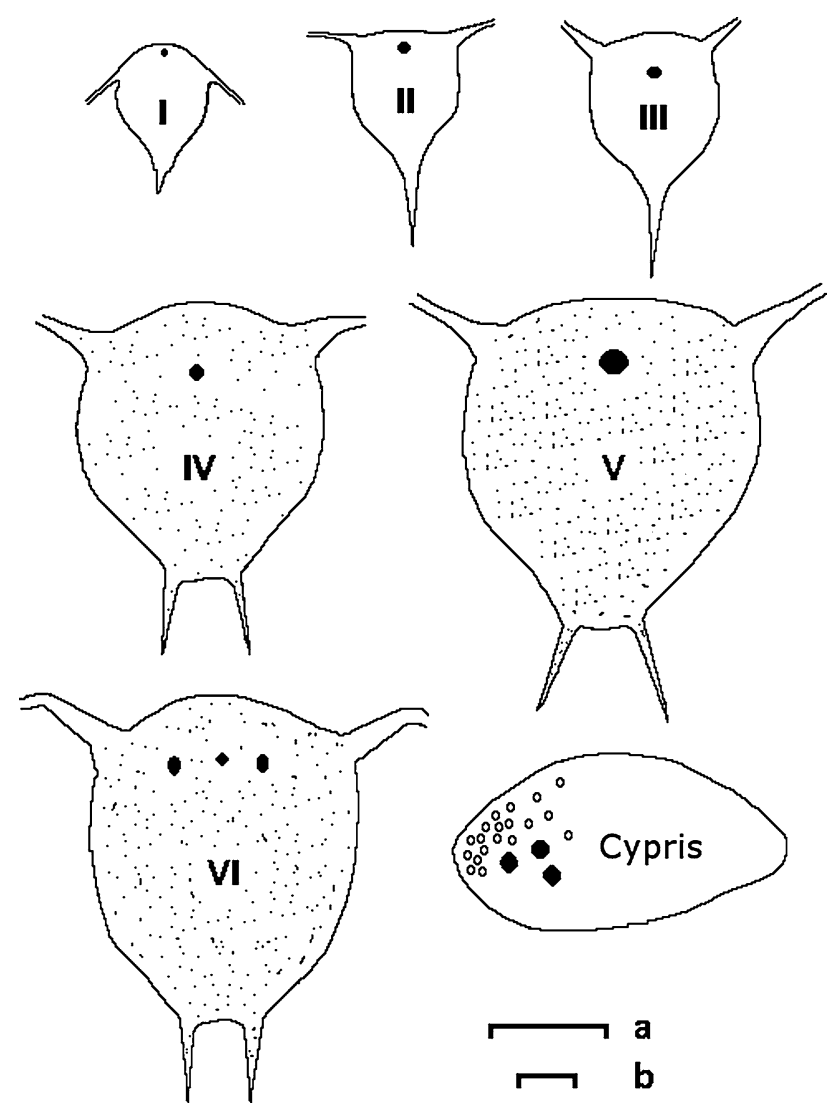

Fig. 1 Megabalanus azoricus; carapace morphology of naupliar stages I-III (scale bar a), naupliar stages IV-VI, and cypris (scale bar b), dots represent spines. Scale bar $(a, b) 100 \mu \mathrm{m}$

spines in stages IV-VI. The shield is much longer than broad and bears multiple spines in stages IV-VI (represented by dots in Fig. 1). Fronto-lateral horns have a medium length, directed forward from stage III. The larvae present relatively short dorsal cephalic spines, especially in the early stages, and relatively long posterior shield spines. A nauplius eye is present in all nauplius stages. The labrum is trilobed (Fig. 2), and the median lobe projects well beyond the lateral lobes in all stages. The arrangement of spines on the abdominal process corresponds with the usual balanoid pattern. An additional distinct feature of this species is the presence of spines all over the carapace and appendages in all stages. As typical of balanoid larvae (e.g., Lee et al. 1999), antennae have one cuspidate and one plumodenticulate seta, whereas mandibles have two cuspidate setae. The mandibular plumodenticulate setae are poorly developed. The number and the type of setae varied little within a given stage (Table 2). Figures 1, 2, 3, 4, 5, 6, and 7 show the body forms, antennules, antennae, and mandibles, respectively, of the successive stages. The setation formulae are listed in Table 2. Sizes of larvae are given in Table 3, and Table 4 shows a comparison of body length data for six species of the genus Megabalanus.
The diagnostic features of the different larval stages can be summarized as follows:

Nauplius I (Figs. 1, 2, 3, 4, 5, 6, 7)

The pear-shaped cephalic shield has a pair of folded fronto-lateral horns, small in size with a dorsal thoracic spine. The anterior margin of the cephalic shield is strongly convex. Frontal filaments are missing. The nauplius eye is situated in a fronto-median position and persists throughout all subsequent stages. The trilobed labrum is without teeth. The abdominal process and the dorsal thoracic spine are rudimentary and almost similar in length. Antennules, antennae, and mandibles have simple setae without fine setules.

\section{Nauplius II (Figs. 1, 2, 3, 4, 5, 6, 7)}

The carapace has extended in all directions and has become bell-shaped with a less convex anterior margin. The fronto-lateral horns have also extended and run parallel to the frontal margin of the cephalic shield. Frontal filaments are presented on the anterior shield margin. The abdominal process and the cephalic shield are well developed, with the latter being longer than the former. The entire lateral margin of the carapace is spinulous with numerous small spines and a pair of preeminent spines. The labrum bears many short setules on each lobe. The distal margin of the median labral lobe bears teeth from this stage onward. The abdominal process terminates in a bifurcate ramus and has a pair of small lateral spines (series 1 spines) and some proximal and distal barbs. Dorsal shield spines are missing. Some setae of the three appendages show numerous fine setules on some setae. There is one pair of abdominal spines, whereas preaxial setae are missing on the antennules.

\section{Nauplius III (Fig. 1, 2, 3, 4, 5, 6, 7)}

The cephalic shield has increased in size in relation to the preceding stages (Table 3). The lateral margin of the cephalic shield is more rounded when compared with previous nauplius stages. The abdominal process bears only one pair of series 1 (distal) spines. The frontal shield margin is slightly convex. The fronto-lateral horns have become slightly thickened and bound forward. The dorsal thoracic spine is barbed and constantly longer than the abdominal process. Several rows of spines are present on the thoraco-abdominal process, and preaxial setae are found on the antennules.

Nauplius IV (Figs. 1, 2, 3, 4, 5, 6, 7)

The cephalic shield has a distinct posterior margin bearing a pair of posterior shield spines. There are numerous small spines covering the shield and appendices. The fronto-lateral horns are deflected forward and 
Fig. 2 Megabalanus azoricus; ventral view of the labra of naupliar stages I-VI. Scale bar $50 \mu \mathrm{m}$
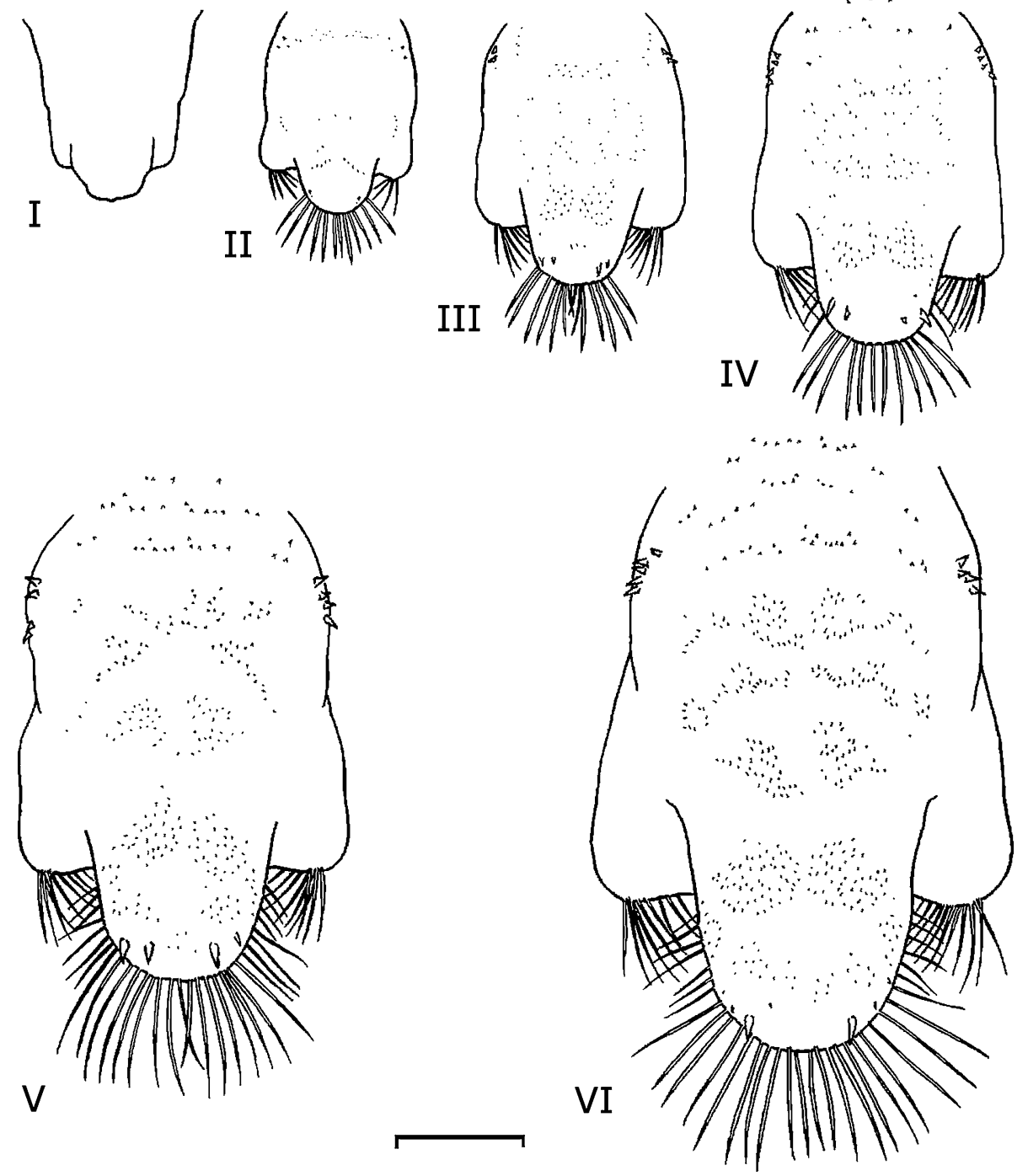

ventrally. The dorsal thoracic spine is by two-thirds longer than the abdominal spine. There are series 1 and 2 of thoracic spines and two median spines. The abdominal process is separated from the carapace, and the entire posterior margin bears both series 1 (distal) and series 2 (proximal) spines. The series 1 spines are larger than those of series 2. The spines of the abdominal series are enlarged to about the same length as the furcal rami. The stem of the abdominal process is armed with a full complement of spines. Two preaxial setae on the antennules represent a diagnostic feature of this naupliar stage. The median lobe of the labrum bears serrated setules, while the lateral lobes still have only simple short setules.

\section{Nauplius V (Figs. 1, 2, 3, 4, 5, 6, 7)}

The cephalic shield has increased in size and length, but the general shape has remained the same as in the fourth nauplius stage. Anterior and lateral margins as well as the dorsal surface of the shield display numerous small spines.
The larvae have well-developed dorsal shield spines along with many small spines on the shield. The dorsal thoracic spine remains barbed, but is now shorter than the abdominal process, and the thoracic spines have taken an armored shape. There are three thoracic spines, arranged in a transverse row, and a small spine on the thoracic spines. Series 1 spines are longer than those of series 2. A pair of series 3 spines appears anterior to the furcal stem in addition to the spines of series 1 and 2 . There are 5-6 pairs of thoracic spines. Three preaxial setae and five postaxial setae on the antennules represent diagnostic features of this naupliar stage.

Nauplius VI (Figs. 1, 2, 3, 4, 5, 6, 7)

Larvae of this stage are easily distinguished from those of other stages by a paired compound eye situated laterally to the nauplius eye. The larvae now possess six pairs of series 2 spines. The primordials of the thoracic appendages of the cypris are now visible on the ventral side through the 
Table 2 Setal formulae for the naupliar stages of different species of the genus Megabalanus

\begin{tabular}{|c|c|c|c|c|c|c|}
\hline \multicolumn{2}{|c|}{ Naupliar stage } & \multirow[t]{2}{*}{ Antennule } & \multicolumn{2}{|l|}{ Antenna } & \multicolumn{2}{|c|}{ Mandible } \\
\hline & & & Exopod & Endopod & Exopod & Endopod \\
\hline \multirow[t]{6}{*}{ I } & M.a. & SSSS:SS:S:S & $4 \mathrm{~S}$ & SSS:SS:SS:SS:G & $4 \mathrm{~S}$ & SSS:SS:SS:SS:G \\
\hline & M.ca. & SSSS:SS:S:S & $6 \mathrm{~S}$ & SSS:SS:SS:SSC:G & $4 \mathrm{~S}$ & SSS:SS:SCS:SC:G \\
\hline & M.co. & SSSS:SS:S:S & $*$ & SSS:SS:SS:SSS:G & $*$ & SSS:SS:SS:SSS:G \\
\hline & M.t. & SSSS:SS:S:S & $5 \mathrm{~S}$ & SSS:SS:SS:SSS:G & $4 \mathrm{~S}$ & SSS:SS:SS:SS:G \\
\hline & M.r. & SSSS:SS:S:S & $5 \mathrm{~S}$ & SSS:SS:SS:SSS:G & $4 \mathrm{~S}$ & SSS:SS:SS:SS:G \\
\hline & M.v. & SSSS:SS:S:S & $5 \mathrm{~S}$ & SSS:SS:SS:SSS:G & $4 \mathrm{~S}$ & SSS:SS:SS:SS:G \\
\hline \multirow[t]{6}{*}{ II } & M.a. & SSPS:SP:P:S & SP:4P:S & PPS:SP:PD:PSC:G & $4 \mathrm{P}: \mathrm{S}$ & SSS:SP:PCP:PC:G \\
\hline & M.ca. & SSPS:SP:P:S & $6 \mathrm{P}$ & PPS:SP:PP:SPC:G & $5 \mathrm{P}$ & SSS:SP:PCS:PC:G \\
\hline & M.co. & SSPS:SP:PS & $*$ & PPS:SP:PD:SPC:G & $*$ & SSS:SP:PCP:PC:G \\
\hline & M.t. & SSPS:SP:P:S & SP:4P:S & PPS:SP:PD:SPC:G & $4 \mathrm{P}: \mathrm{S}$ & SSS:SP:PSdC:sPPC:G \\
\hline & M.r. & SSPS:SP:P:S & SP:4P:S & PPS:SP:PD:PSC:G & $4 \mathrm{P}: \mathrm{S}$ & SSS:SD:DSC:PC:G \\
\hline & M.v. & SSPS:SP:P:S & SP:4P:S & PPS:SP:PD:PSC:G & $4 \mathrm{P}: \mathrm{S}$ & SSS:SD:DSC:PC:G \\
\hline \multirow[t]{6}{*}{ III } & M.a. & S:PSPP:SP:P:S & $7 \mathrm{P}$ & PPP:SP:PD:PSCS:G & $4 \mathrm{P}$ & SSS:SPS:PCP:PCP:G \\
\hline & M.ca & S:PSPP:SP:P:S & $7 \mathrm{P}$ & PPP:SP:PP:SPCS:G & $5 \mathrm{P}$ & SSS:SPS:PCP:PCD:G \\
\hline & M.co. & S:PSPP:SP:P:S & $*$ & PPP:SP:PD:SPCS:G & $*$ & SSS:SPS:PCP:PCD:G \\
\hline & M.t. & S:PSPP:SP:P:S & $7 \mathrm{P}$ & PPP:SP:PD:PSPC:G & $4 \mathrm{P}: \mathrm{S}$ & SSS:SPS:PCD:sPCP:G \\
\hline & M.r. & S:PSPP:SP:P:S & $7 \mathrm{P}$ & PPP:SP:PD:PSSC:G & $4 \mathrm{P}: \mathrm{S}$ & SSS:SDS:DDC:sPCP:G \\
\hline & M.v. & S:PSPP:SP:P:S & $7 \mathrm{P}$ & PPP:SP:PD:PSSC:G & $4 \mathrm{P}: \mathrm{S}$ & SSS:SDS:DDC:sPCP:G \\
\hline \multirow[t]{6}{*}{ IV } & M.a. & S:P:PSPP:SP:P:S & $8 \mathrm{P}$ & PPPPS:SPP:PD:PSCD:G & $5 \mathrm{P}$ & SSSS:SSPP:PCDS:PPC:G \\
\hline & M.ca & S:P:PSPP:SP:P:S & $9 \mathrm{P}$ & PPPPS:SPS:PP:SPCP:G & $5 \mathrm{P}$ & SSSS:SPP:PCP:PCP:G \\
\hline & M.co. & S:P:PSPP:SP:P:S & $*$ & PPPSS:SPS:PD:SPCD:G & $*$ & SSSS:SSPP:PCDS:PPC:G \\
\hline & M.t. & SP:PSPP:SP:P:S & $9 \mathrm{P}$ & PPSPP:SPS:PD:PSPC:G & $5 \mathrm{P}$ & SSSS:SPP:SPCD:sPPC:G \\
\hline & M.r. & SP:PSPP:SP:P:S & $9 \mathrm{P}$ & PPSPS:SPS:PD:DSPC:G & $5 \mathrm{P}$ & SSSS:SDD:SDDC:sPCP:G \\
\hline & M.v. & SP:PSPP:SP:P:S & $9 \mathrm{P}$ & PPSPS:SPS:PD:PSPC:G & $5 \mathrm{P}$ & SSSS:SPD:SDDC:sPCP:G \\
\hline \multirow[t]{6}{*}{ V } & M.a. & S:S:P:PSPP:SP:P:P:S & $11 \mathrm{P}$ & PPPPS:SPP:PD:PSCD:G & 5PS & SSSS:SSPP:SPCD:PPC:G \\
\hline & M.ca & S:P:PSPP:SP:S:PS:S & $9 \mathrm{P}$ & PPPSS:PPS:PP:SPCP:G & 5PS & SSSS:SPP:PSCP:PCP:G \\
\hline & M.co. & S:S:P:PSPP:SP:P:S & $*$ & PPPPS:SPP:PD:SPCD:G & $*$ & SSSS:SSPP:SPCD:PPC:G \\
\hline & M.t. & S:P:P:PSPP:SP:S:P:S & $11 \mathrm{P}$ & PPSPP:SPP:PD:PSPC:G & $5 \mathrm{PS}$ & SSSS:SPD:SPCD:sPPC:G \\
\hline & M.t. & S:P:P:PSPP:SP:S:P:S & $11 \mathrm{P}$ & PPSPP:SPP:PD:DSDC:G & $5 \mathrm{PS}$ & SSSS:SSDD:SDDC:sPDC:G \\
\hline & M.v. & S:S:P:PSPP:SP:S:P:S & $11 \mathrm{P}$ & PPSPP:SPP:PD:PSPC:G & $5 \mathrm{PS}$ & SSSS:SSDD:SDDC:sPPC:G \\
\hline \multirow[t]{6}{*}{ VI } & M.a. & S:P:P:PSPP:SP:P:PS:S & $12 \mathrm{P}$ & PPPPS:SPP:PD:PSCD:G & $6 \mathrm{P}$ & SSSS:SSPP:SPCD:PPC:G \\
\hline & M.ca & S:P:P:PSPP:SP:P:PS:S & $12 \mathrm{P}$ & PPPSPS:PPS:PP:SPCP:G & $6 \mathrm{P}$ & SSSS:SPP:PCP:PCP:G \\
\hline & M.co. & S:P:P:PSPP:SP:P:S:SP:S & $*$ & PPPPS:SPP:PD:SPCD:G & $*$ & SSSS:SSPP:SPCD:PCD:G \\
\hline & M.t. & S:P:P:PSPP:SP:P:PS:S & $12 \mathrm{P}$ & PPSPP:SPP:PD:SPCP:G & $6 \mathrm{P}$ & SSSS:SSPD:SDCD:sPPC:G \\
\hline & M.r. & S:P:P:PSPP:SP:P:PS:S & $12 \mathrm{P}$ & PPSPP:SPP:PD:DDDC:G & $6 \mathrm{P}$ & SSSS:SSDD:SDDC:sDDC:G \\
\hline & M.v. & S:P:P:PSPP:SP:P:PS:S & $12 \mathrm{P}$ & PPSPP:SPP:PD:PSPC:G & $6 \mathrm{P}$ & SSSS:SSDD:SDDC:sPPC:G \\
\hline
\end{tabular}

M.a. M. azoricus (present paper), M.ca. M. californicus (Miller and Roughgarden 1994), M.co. M. coccopoma (Severino and Resgalla 2005), M.t. M. tintinnabulum (Thiyagarajan et al. 1997), M.r. M. rosa, M.v. M. volcano (Kado and Hirano 1994)

Setal types: $S$ and $s$ simple, $P$ plumose, $C$ cuspidate, $D$ plumodenticulate, $G$ gnathobase

* Data missing

cuticle. The abdominal process has been considerably enlarged over the fifth nauplius stage, and six pairs of small spines mark the developing cirriform appendages. Three pre- and six postaxial setae on the antennules are diagnostic features of this nauplius. The compound eyes become increasingly pigmented through this naupliar stage.
Cypris

Larvae at the anterior end are rounded without any deflections, and the dorsal margin is smoothly curved. The ventral margin behind the compound eyes is rather straight. The posterior end is narrowly curved to pointed, with no upward 


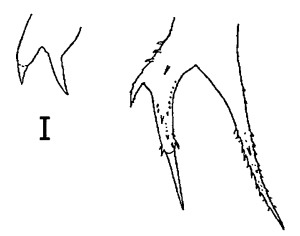

II

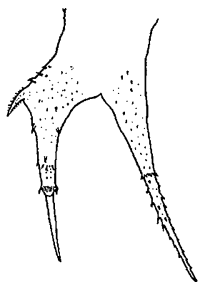

III

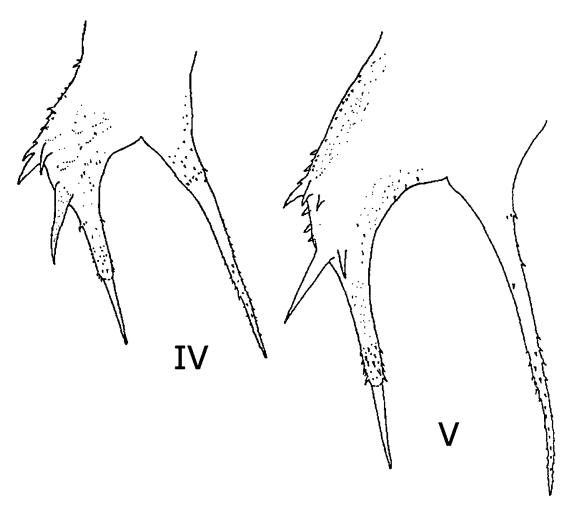

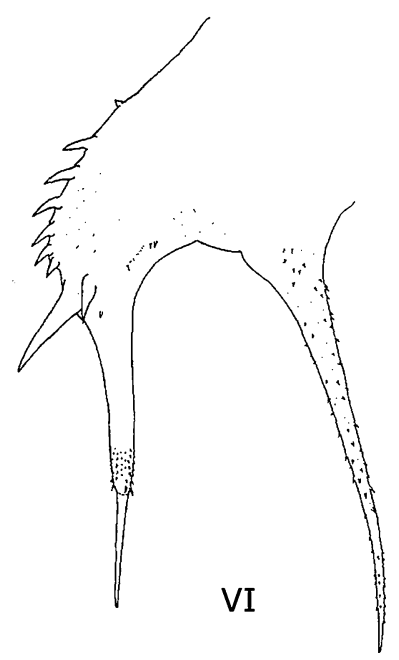

Fig. 3 Megabalanus azoricus; lateral view of the thoraco-abdominal process of naupliar stages I-VI. Scale bar $100 \mu \mathrm{m}$
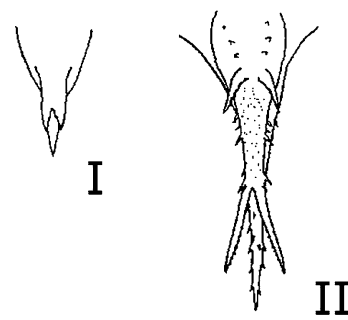

II
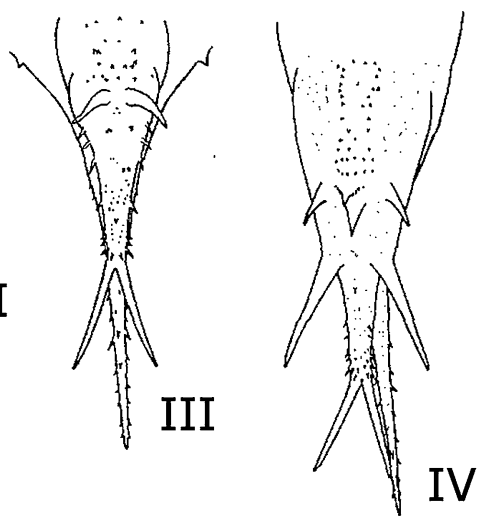

IV
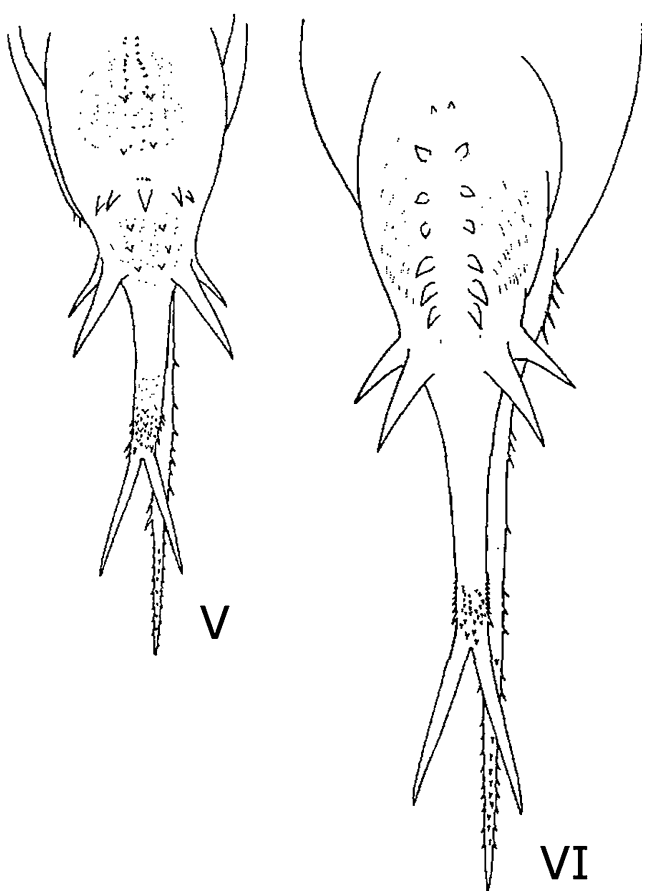

Fig. 4 Megabalanus azoricus; ventral view of the thoraco-abdominal process of naupliar stages I-VI. Scale bar $100 \mu \mathrm{m}$

turn. The surface of the carapace, which is covered with tiny spines, represents a diagnostic feature. The head area is packed with numerous oil droplets. The antennules are reduced and terminated at the $4^{\text {th }}$ segment. The larva presents six pairs of appendages on the thoracic region and a caudal furca. The nauplius eye persists in addition to the paired compound eye.

\section{Discussion}

A number of other species of Megabalanidae have been reared under controlled laboratory conditions (e.g., Kado and Hirano 1994; Severino and Resgalla 2005; Egan and Anderson 1987), allowing for comparisons with the present findings on M. azoricus (Table 4). 

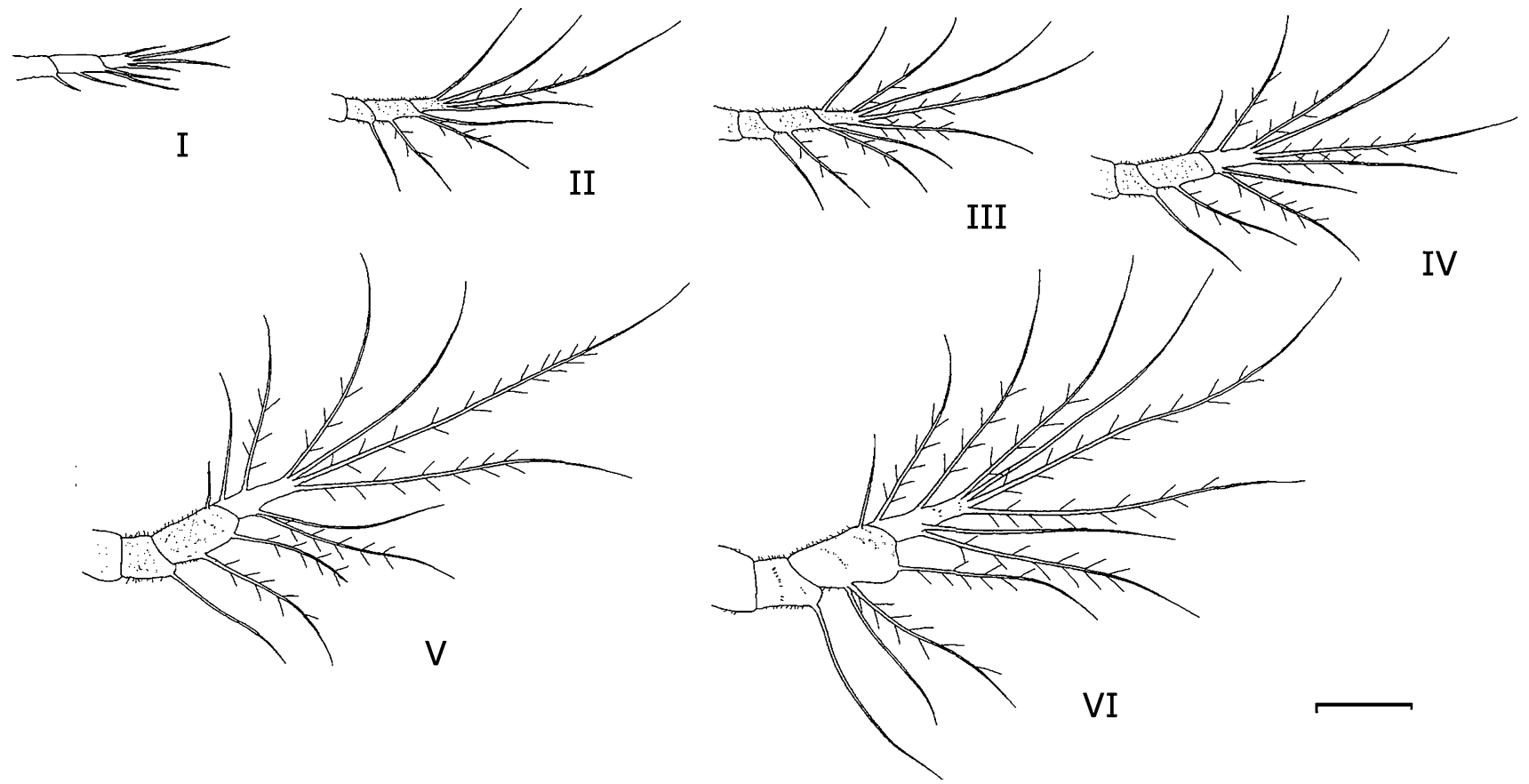

Fig. 5 Megabalanus azoricus; antennules of naupliar stages I-VI. Scale bar $100 \mu \mathrm{m}$

Fig. 6 Megabalanus azoricus; antennae of naupliar stages IVI. Scale bar $100 \mu \mathrm{m}$
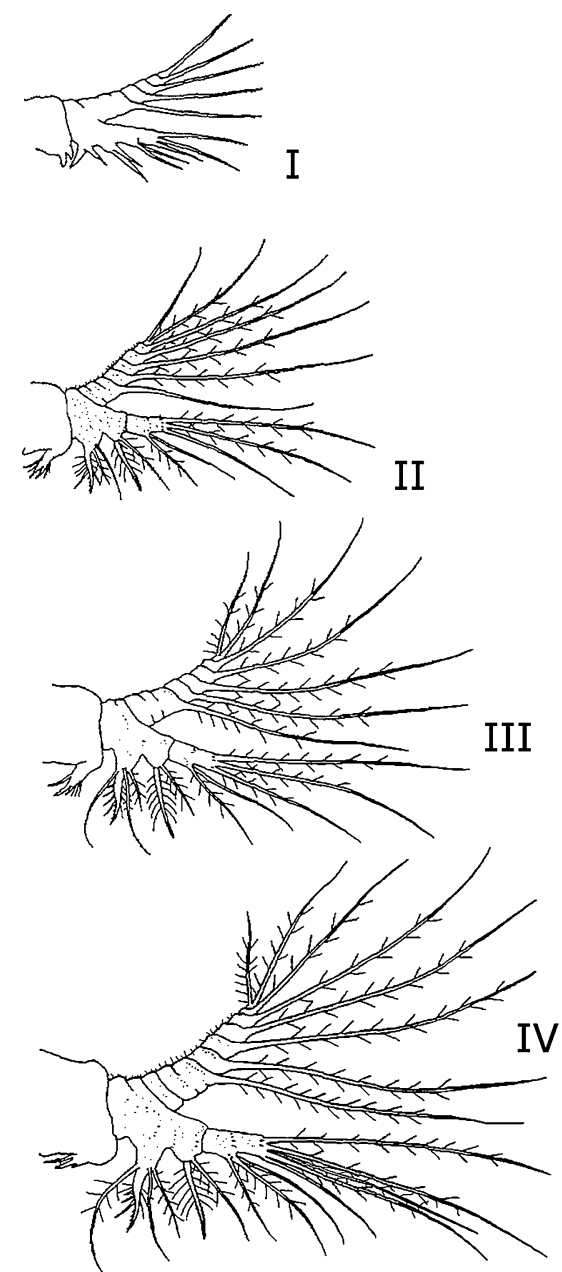
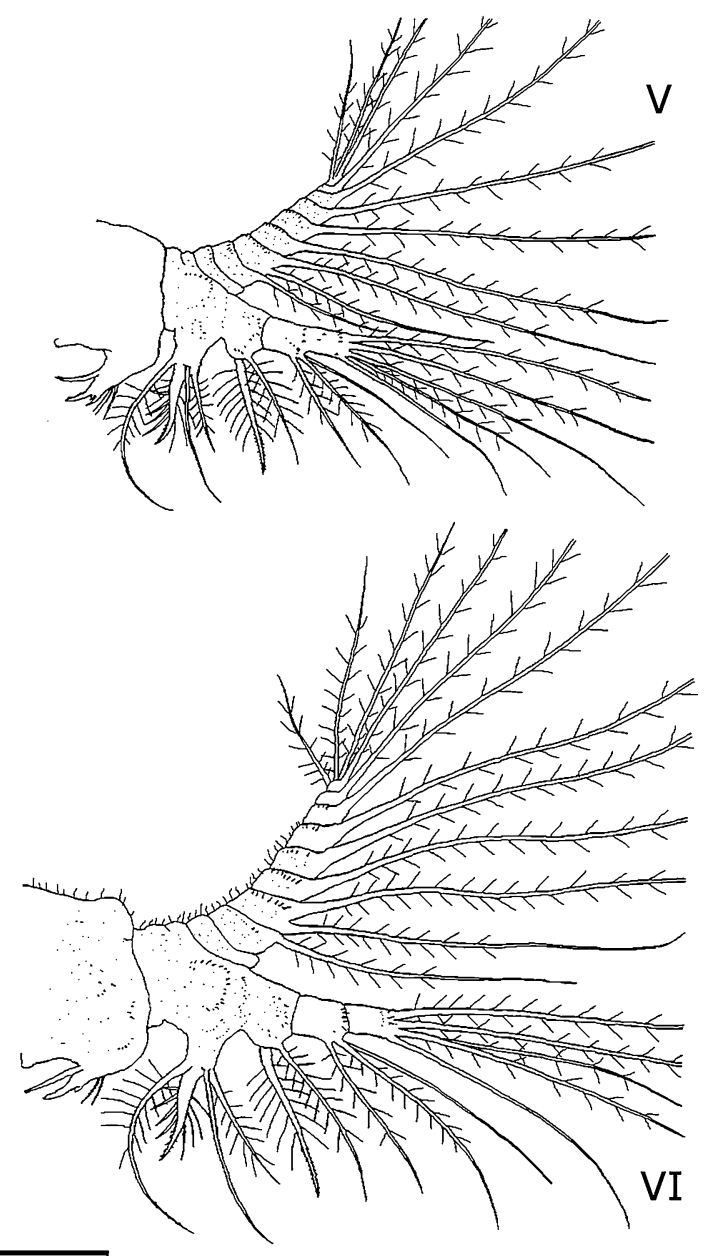


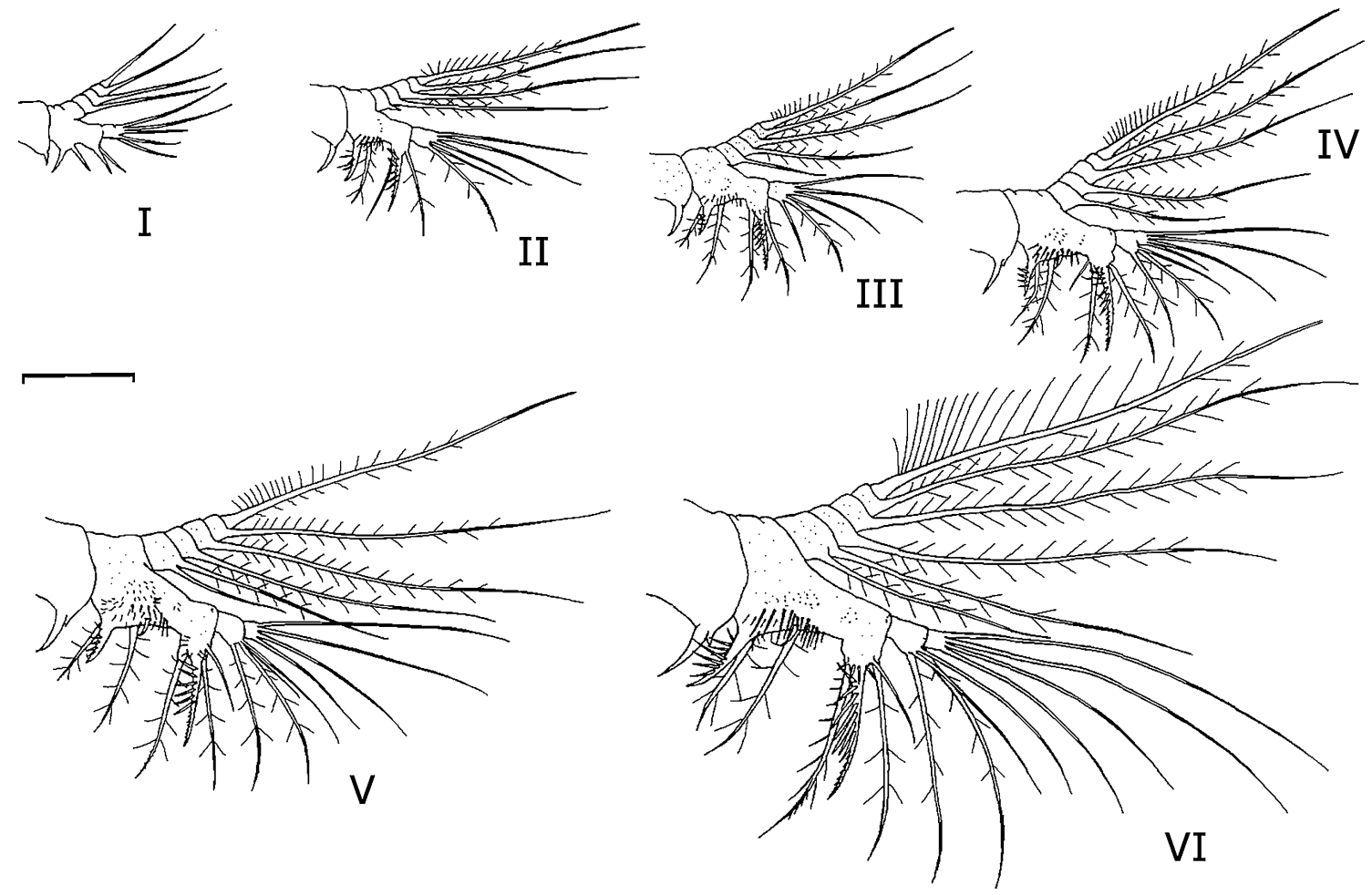

Fig. 7 Megabalanus azoricus; mandibles of naupliar stages I-VI. Scale bar $100 \mu \mathrm{m}$

Table 3 Sizes ( $\mu \mathrm{m}$, mean $\pm \mathrm{SD}, N=10$ per stage) of the naupliar stages (I-VI) and the cypris larva of M. azoricus

\begin{tabular}{|c|c|c|c|c|c|}
\hline Stage & TL & SL & SP & SW & FL \\
\hline I & $261 \pm 12.9$ & & & $163 \pm 23.1$ & $26 \pm 7.1$ \\
\hline II & $357 \pm 11.8$ & & & $178 \pm 10.2$ & $34 \pm 12.7$ \\
\hline III & $413 \pm 9.0$ & & & $212 \pm 11.8$ & $43 \pm 13.0$ \\
\hline IV & $722 \pm 17.6$ & $444 \pm 9.4$ & $133 \pm 7.8$ & $418 \pm 11.8$ & $122 \pm 6.7$ \\
\hline V & $905 \pm 11.8$ & $593 \pm 12.7$ & $184 \pm 6.7$ & $518 \pm 9.8$ & $160 \pm 8.0$ \\
\hline VI & $912 \pm 11.8$ & $606 \pm 10.2$ & $191 \pm 12.7$ & $530 \pm 7.3$ & $166 \pm 9.0$ \\
\hline Cypris & $602 \pm 8.6$ & & & $306 \pm 9.8$ & \\
\hline
\end{tabular}

$T L$ total length, $S L$ shield length, $S P$ length of posterior shield spine, $S W$ shield width and cypris depth, respectively, $F L$ length of fronto-lateral horns

Table 4 Total length $(\mu \mathrm{m}$, mean $\pm \mathrm{SD})$ of naupliar stages I-VI observed in larval cultures of different species of the genus Megabalanus

\begin{tabular}{|c|c|c|c|c|c|c|}
\hline Nauplius & M. azoricus & M. californicus & M. coccopoma & M. tintinnabulum & M. rosa & M. volcano \\
\hline I & $261 \pm 12.9$ & $394 \pm 10$ & $222-248$ & 264 & $245 \pm 9$ & $229 \pm 7$ \\
\hline II & $357 \pm 11.8$ & $454 \pm 8$ & $364-390$ & 404 & $434 \pm 14$ & $390 \pm 9$ \\
\hline III & $413 \pm 9.0$ & $547 \pm 7$ & $439-469$ & 516 & $503 \pm 11$ & $476 \pm 14$ \\
\hline IV & $722 \pm 17.6$ & $702 \pm 7$ & $560-634$ & 610 & $604 \pm 27$ & $552 \pm 20$ \\
\hline V & $905 \pm 11.8$ & $798 \pm 11$ & 737-806 & 784 & $780 \pm 25$ & $670 \pm 33$ \\
\hline VI & $912 \pm 11.8$ & $1,028 \pm 24$ & $869-896$ & 880 & $963 \pm 33$ & $941 \pm 35$ \\
\hline
\end{tabular}

M. azoricus - present study; M. californicus-Miller and Roughgarden 1994; M. coccopoma-Severino and Resgalla 2005; M. tintinnabulumThiyagarajan et al. 1997, no SD given by the authors; M. rosa and M. volcano-Kado and Hirano 1994

The larvae of M. azoricus are similar to those of other species of the genus described so far (Tables 2, 4). The larvae possess a pubescent trilobite labrum and a pair of posterior thoracic spines in stages IV-VI. Like other species of the genus, M. azoricus presents one pair of (abdominal) spines on the ventral thorax in the stages II 
and III, four pairs in stage IV (two thoracic and two abdominal), five in stage $\mathrm{V}$ (two abdominal and three thoracic), and eight in stage VI (two abdominal and six thoracic) (Figs. 2, 3, 4, 5, 6, 7).

The subfamily Megabalaninae erected by Newman (1979) comprises three genera, Megabalanus, Notomegabalanus, and Austromegabalanus. The two latter genera show an austral distribution, while Megabalanus is a warm-temperate genus (Egan and Anderson 1987). In this paper, comparisons will be made only with species of the genus Megabalanus.

Observations showed that $M$. azoricus requires $14 \pm 2$ days to reach the cypris stage in laboratory culture at $20{ }^{\circ} \mathrm{C}$ (see Table 1). For the different species of the genus, Megabalanus reared under the same conditions, generally ranged between 10 and 23 days (e.g., Egan and Anderson 1987, 1988; Choi et al. 1992; Thiyagarajan et al. 1997; Yan and Chan 2001: Severino and Resgalla 2005; Lopez et al. 2008). A larval development taking 13-15 days is usual among warm-water barnacle species reared at $20{ }^{\circ} \mathrm{C}$ (Kado and Hirano 1994; Anil et al. 1995). With respect to larval size, small differences have been observed within the genus (Table 4): In the first larval stage, larvae of $M$. azoricus have approximately the same mean size as those of M. rosa. In the naupliar stages II and III, however, they are smaller than the larvae of other species of Megabalanus. In the stages IV and V, nauplii of $M$. azoricus are larger, and in stage VI smaller than the nauplii of M. californicus, M. rosa, and M. vulcano (Egan and Anderson 1987, 1988; Choi et al. 1992; Thiyagarajan et al. 1997; Yan and Chan 2001; Severino and Resgalla 2005; Lopez et al. 2008).

Laboratory conditions allow for managing the extrinsic factors (e.g., water temperature and food availability), which intervene in the intrinsic mechanisms controlling larval development (Crisp and Spencer 1958; Thiyagarajan et al. 2003). The water temperature in the Azores ranges between $18{ }^{\circ} \mathrm{C}$ (winter) and $23{ }^{\circ} \mathrm{C}$ (summer), so it is possible that in summer, the length of the larval development of $M$. azoricus decreases, as it has been reported for other cirripeds (e.g., Barnes and Barnes 1965; Anil et al. 1995, 2001; Qiu and Qian 1997; Thiyagarajan et al. 2003). Except for body size, larval morphological features such as body shape, spines on abdomen, and setation of the appendages are not likely to vary between larvae reared in laboratory and those collected from natural plankton (Miller and Roughgarden 1994).

Plumodenticulate setae and mandibular spines are features of the nauplii of many megabalanidae species (Egan and Anderson 1987) and are also displayed on the naupliar appendages of $M$. azoricus. The setation of the terminal segment of the naupliar antennule of this species in stages III-V is also typical of the most megabalanidae nauplii
(Egan and Anderson 1987, 1988; Choi et al. 1992; Kado and Hirano 1994; Miller and Roughgarden 1994; Thiyagarajan et al. 1997, Yan and Chan 2001; Severino and Resgalla 2005; Lopez et al. 2008).

In the Azores, the three most common species of acorn barnacles living in the intertidal and the shallow subtidal are Chthamalus stellatus, Tesseropora atlantica, and $M$. azoricus (Southward 1998). In relation to adult size, the biggest one is $M$. azoricus, and the same phenomenon applies to the larvae. For example, the nauplii of Chthamalus stellatus have a total length of $213 \mu \mathrm{m}$ (nauplius I) and $508 \mu \mathrm{m}$ (nauplius VI), respectively (Burrows et al. 1999; Ross et al. 2003). For the same stages, $M$. azoricus reaches 261 and $912 \mu \mathrm{m}$, respectively. Nauplii of Tesseropora atlantica are missing in the plankton, as these are retained in the mantle cavity until the cypris stage is reached (Costa and Jones 2000).

The present paper describes the complete larval development of M. azoricus. This knowledge not only allows for a taxonomic identification but also for staging of larvae from field samples as many larval characters vary among the different larval stages (Lang 1979; Lee and Shim 2000; Ross et al. 2003). Reliable identification and staging of larvae are the basis for studies on the larval ecology, behavior, dispersal, and recruitment. All these aspects of larval biology have important implications for population dynamics and community ecology. The identification of barnacle larvae in plankton samples is also important for an early detection of the arrival and establishment of closely related exotic balanids (Torres et al. 2011).

Megabalanus azoricus is commercially exploited. The knowledge of its larval biology is highly important for a sustainable fisheries management and for assessing the feasibility of an economically productive aquaculture of the species (Anger 2006). Ultimately, the data of the present study may be useful for comparative studies on barnacle larval morphology and for phylogenetic interpretations of Atlantic Cirripedia, combining the approaches of evolutionary and developmental biology (Hoßfeld and Olsson 2003).

Acknowledgments We thank João Brum and Dr. Paulo Torres for technical assistance, two anonymous reviewers, and Helgoland Marine Research editor for their useful comments and the vital suggestions on our manuscript. This research was funded by the research project POCI/MAR/58185/2004 and a FRCT/2007/M 3.1.2 grant awarded to the first author.

\section{References}

Anderson DT (1994) Barnacles: structure, function, development and evolution. Chapman and Hall, New York

Anger K (2006) Contributions of larval biology to crustacean research: a review. Invertebr Reprod Dev 49:175-205 
Anil AK, Chiba K, Okamoto K, Kurokura H (1995) Influence of temperature and salinity on larval development of Balanus amphitrite: implications in fouling ecology. Mar Ecol Prog Ser 118:159-166

Anil AK, Desai D, Khandeparker L (2001) Larval development and metamorphosis in Balanus amphitrite Darwin (Cirripedia; Thoracica): significance of food concentration, temperature and nucleic acids. J Exp Mar Biol Ecol 263:125-141

Barnes H, Barnes M (1965) Egg size, nauplius size, and their variation with local, geographical, and specific factors in some common cirripedes. J Anim Ecol 34:391-402

Branscomb E, Vedder K (1982) A description of the naupliar stages of the barnacles Balanus glandula Darwin, Balanus cariosus Pallas, and Balanus crenatus Bruguière (Cirripedia, Thoracica). Crustaceana 42:83-95

Brown S, Roughgarden J (1985) Growth, morphology, and laboratory culture of larvae of Balanus glandula (Cirripedia: Thoracica). J Crustac Biol 5:574-590

Burrows M, Hawkins S, Southward A (1999) Larval development of the intertidal barnacles Chthamalus stellatus and Chthamalus montagui. J Mar Biol Ass UK 79:93-101

Chan B (2003) Studies on Tetraclita squamosa and Tetraclita japonica II: larval morphology and development. J Crustac Biol 23:522-547

Choi K, Anderson D, Kim C (1992) Development of the megabalanine balanomorph Megabalanus rosa (Pilsbry) (Cirripedia, Balanidae). Proc Linn Soc NSW 113:175-184

Costa A, Jones M (2000) The genus Tesseropora (Cirripedia: Tetraclitidae) from São Miguel, Azores. Arquipel Life Mar Sci 2:71-78

Crisp D (1976) The role of the pelagic larva. In: Spencer-Davies P (ed) Perspectives in experimental biology, vol 1. Zoology. Pergamon Press, Oxford, pp 145-155

Crisp D, Spencer C (1958) The control of the hatching process in barnacles. Proc R Soc Lond B 149:278-299

Dionísio M, Rodrigues A, Costa A (2007) Reproductive biology of Megabalanus azoricus (Pilsbry), the Azorean Barnacle. Invertebr Reprod Dev 50:155-162

Egan A, Anderson D (1987) Larval development of the Megabalanine Balanomorph Austromegabalanus nigrescens (Lamarck) (Cirripedia, Balanidae). Aust J Mar Freshw Res 38:511-522

Egan A, Anderson D (1988) Larval development of the coronuloid barnacles Austrobalanus imperator (Darwin), Tetraclitella purpurascens (Wood) and Tesseropora rosea (Krauss) (Cirripedia, Tetraclitidae). J Nat Hist 22:1379-1405

Foster B (1967) The early stages of some New Zealand shore barnacles. Tane 13:33-42

Hoßfeld U, Olsson L (2003) The road from Haeckel: the Jena tradition in evolutionary morphology and the origins of "EvoDevo". Biol Philos 18:285-307

Kado R, Hirano R (1994) Larval development of two Japanese megabalanine barnacles, Megabalanus volcano (Pilsbry) and Megabalanus rosa (Pilsbry) (Cirripedia, Balanidae), reared in the laboratory. J Exp Mar Biol Ecol 175:17-41

Lang W (1979) Larval development of shallow water barnacles of the Carolinas (Cirripedia: Thoracica) with keys to naupliar stages. NOAA Tech Rep NMFS 421:1-39

Lee C, Shim JM (2000) Larval development of Membranobalanus koreanus Kim and Kim, 1983, reared in the laboratory (Cirripedia, Thoracica). Crustaceana 73:393-406

Lee C, Shim J, Kim C (1999) Larval development of Balanus reticulatus Utinomi, 1967 (Cirripedia, Thoracica) and a comparison with other barnacle larvae. J Plankton Res 21:2125-2142
Lopez D, Espinoza E, Lopez B, Santibanez A (2008) Molting behavior and growth in the giant barnacle Austromegabalanus psittacus (Molina, 1782). Rev Biol Mar Ocean 43:607-613

López DA, López BA, Pham CK, Isidro EJ, De Girolamo M (2010) Barnacle culture: background, potential and challenges. Aquat Res 41:e367-e375

Miller K, Roughgarden J (1994) Descriptions of the larvae of Tetraclita rubescens and Megabalanus californicus with a comparison of the common barnacle larvae of the Central California Coast. J Crustac Biol 14:579-600

Newman W (1965) Prospectus on larval cirriped setation formulae. Crustaceana 9:51-56

Newman WA (1979) On the biogeography of balanomorph barnacles of the southern ocean including new balanid taxa: a subfamily, two genera and three species. In: Proceedings of the international symposium on marine biogeography and evolution of the southern hemisphere, vol 1, pp 279-306

OSPAR (2011) Publication number: 556/2011. OSPAR's background document on ecological quality objectives for threatened and/or declining habitats, OSPAR commission, London (www.ospar. org)

Pham CK, Higgins RM, De Girolamo M, Isidro E (eds) (2008) Developing a sustainable aquaculture industry in the azores. Arquipélago. Life and Marine Sciences. Supplement 7:xiii+81 $\mathrm{pp}$

Qiu J, Qian P (1997) Effects of food availability, larval source and culture method on larval development of Balanus amphitrite amphitrite Darwin: implications for experimental design. J Exp Mar Biol Ecol 217:47-61

Ross P, Burrows M, Hawkins S, Southward A, Ryan K (2003) A key for the identification of the nauplii of common barnacles of the British Isles, with emphasis on Chthamalus. J Crustac Biol 23:328-340

Severino A, Resgalla C (2005) Larval development of the Megabalanus coccopoma (Darwin, 1854) and temporal variation in Itapocoroy bay (Santa Catarina, Brazil). Atlantica 27:5-16

Southward A (1998) New observations on Barnacles (Crustacea: Cirripedia) of the Azores Region. Arquipel Life Mar Sci 16A:11-27

Thiyagarajan V, Venugopalan V, Subramoniam T, Nair K (1997) Naupliar development of Megabalanus tintinnabulum (Cirripedia, Balanidae) reared in the laboratory. J Crustac Biol $17: 332-342$

Thiyagarajan V, Harder T, Qiu J, Qian P (2003) Energy content at metamorphosis and growth rate of the early juvenile barnacle Balanus amphitrite. Mar Biol 143:543-554

Torres P, Costa A, Dionísio M (2011) New alien barnacles in the Azores and some remarks on the invasive potential of Balanidae. Helgol Mar Res 66:513-522

Wirtz P, Araújo R, Southward A (2006) Cirripedia of Madeira. Helgol Mar Res 60:207-212

WWF (2010) Living planet report 2010. Biodiversity, biocapacity and development, WWF international, Gland, Switzerland (www. panda.org)

Yan Y (2003) Larval development of the barnacle Chinochthamalus scutelliformis (Cirripedia: Chthamalidae) reared in the laboratory. J Crustac Biol 23:513-521

Yan Y, Chan B (2001) Larval development of Chthamalus malayensis (Cirripedia: Thoracica) reared in the laboratory. J Mar Biol Ass UK 81:623-632 